\title{
Corporate Governance Practices in Higher Education Institutions: The UK vs Bahrain
}

\author{
Marwan M. Abdeldayem (Corresponding author) \\ College of Administrative Sciences \\ Applied Science University (ASU)-Kingdom of Bahrain \\ Email: Marwan.abdeldayem@asu.edu.bh \\ Saeed H. Aldulaimi \\ College of Administrative Sciences \\ Applied Science University (ASU)-Kingdom of Bahrain
}

Received: September 24, 2018 Accepted: October 21, 2018 Published: October 31, 2018

doi:10.5296/ijld.v8i4.13841 URL: https://doi.org/10.5296/ijld.v8i4.13841

\begin{abstract}
This research aims to investigate the application of leadership and governance in higher education organizations in the Kingdom of Bahrain and the UK. The study also intends to gather evidences on the practices of academic management in different cultures. The methods of the study relies on reading lists of governance standards from several advanced educational institutions and uses a "comparative methodology" based on the data from the Kingdom of Bahrain and The UK. This research reviews the various models of "the higher education governance" and discuss the strengths and weaknesses of each model. The study employs the three principles of UNDP (Transparency, Participation and Accountability) to assess application of leadership and governance in higher education institutions.

The findings of this study reveal that Arab universities need to perceive the significance of clarifying the reason for governance. The examination likewise distinguishes the significance of relating their job and commitment to the procedure of change to the learning based economy and world informatics. Also, it features the need of broadening the cooperation of stakeholders in the key basic leadership.

The importance of this study lies in examining whether the governance standards are associated with practical application in universities. Also it examines whether there is an
\end{abstract}


influence of the culture and social aspects on the application and understanding of these standards. The significance of receiving administration measures in the Arab world lies in its possibility to change the HE organizations' practices, and increment their ability for greatness and aggressiveness. Thus, ensures the autonomy of advanced education alongside its quality and viability particularly with respect to their yield and status locally and internationally.

Keywords: Leadership, governance, higher education, organizational theory, UK, Kingdom of Bahrain

\section{Introduction}

The former president of Harvard University Derek Bok stated that "If you think education is expensive, try ignorance" and also Nelson Mandela said "Education is the most powerful weapon which you can use to change the world". Higher education has witnessed significant change over the last two decades, and in the Arab world in particular there is loudly movements. Despite holding degrees in the past was granted to the exclusive of the elite, however in the mid-twentieth century, higher education became accessible to the majority of people. Yet there is a gap between the labor market demand of specific skills and high professional graduates and the reality of classical and ordinary graduates.

Clearly, Arab world is standing up to an insufficiency in organization in various territories, including advanced education. Advanced education is the wellspring from which society draws its future pioneers and addresses the necessities of the overall population (Altman, 1996). Along these lines, Arab society needs more than ever to sustain its propelled training organization with a particular ultimate objective to address the present troubles and demands. Bedouin propelled instruction foundations need to strengthen their internal organization to address those new challenges and offer look for after a more promising time to come. "Around $36 \%$ of all HEIs are private in nature, while private fragment universities address more than $80 \%$ of all schools in Bahrain, Lebanon, Palestine, Qatar, and the United Arab Emirates. On the other hand, private schools incorporate under $20 \%$ of the total in Algeria, Iraq, Libya, and Morocco" (Wilkens, 2011).

There has been an emotional increment in colleges related with Western nations and remote branch grounds, specifically in the United Arab Emirates and Qatar (Lasanowski, 2010). "The challenge for all societies is to create a system of governance that promotes, supports and sustains human development - especially for the poorest and most marginal. But the search for a clearly articulated concept of governance has just begun" (UNDP, 1997a: 2)

On opposite, the UK has been known at the highest point of HE part strategy changes with particular accentuation on animating sound budgetary administration by means of good inner administration courses of action, more noteworthy open responsibility and straightforwardness and more grounded execution (Vidovich \& Currie, 2011; Parker, 2012; Rowlands, 2013). Legislative changes and arrangements forced by governments on open and private associations around the globe have been intended to enhance their administration game plans (Shattock, 2013).

Most Western nations attempted to manage the progressions noted above by actualizing an 
expansive number of basic changes went for changing the control examples of advanced education (De Boer \& File, 2009; Norton, 2014; McLendon, 2003). For instance, "the US; and in European nations, many changes were endeavored from the mid-1980s, with the point of rebuilding the connection between the state, society, and organizations of advanced education" (Dobbins \& Knill, 2009), Eurydice as referred to in De Boer, (Huisman \& Meister-Scheytt, 2010). "Administration" in its general shape alludes to how people in general together with the private division tackle social issues and produce social openings, and additionally to how they manage and tend to those under their support. Moreover, administration alludes to the division of obligation and responsibility with respect to the specialist to achieve choices (Corcoran, 2004).

In the present paper we look to audit changed models of advanced education administration versus the UK model, and furthermore to achieve conclusions and suggestions concerning the Arab models of administration. Shared governance is a "system of governance whereby the decision making capacity of the institution is shared by those affected by the decisions; these include the boards, administrators, faculty, staff and students" (Schuetz, 1999). Hamdan (2015), revealed that there are general debilitation in markers of advanced education administration in Arabs world. Moreover, the Arab college has not making the important move to pull in the gifts and utilize them to help the task of improvement. What's more, the Arab colleges overpowering the shortcoming of financing and vigorously reliance on government spending plan. In any case, the truth of advanced education in Arab world can't be isolated from the impact from alternate factors that add to the improvement of the nation.

\section{Theoritical Framework and Literature Review}

The administration of colleges developed after the administration drifts openly organizations (Dixon \& Coy, 2007; Shattock, 2006, 2013). Australian and abroad colleges have moved far from the customary self-administration model of college administration to a model all the more firmly lined up with business partnerships (Buckland, 2004; Shattock, 2008, 2013) with "an ascent in the "official"" (Shattock, 2013: 217). Administration in HE in Australia

\subsection{Models of Governance}

As shown by Clark's (1983) models of advanced education administration can be depicted by triangle that delineates the methodology of cutting edge instruction as shared relations between grandstand controls, the state, and insightful religious government (see also: Olsen, 2007). The models used in the contrasting nations are not just a sign of current begins and surely understood practices (for instance: mercantilism, schools as affiliations) rather they are likewise settled in the genuine beginnings of the colleges, especially the Humboldt Ian and the Napoleonic customs in Europe (Dobbins et al., 2010). In this research effort we will demonstrate the three standard models as indicated by the division recommended by Dobbins et al. (2011): "the state-centered model", "oneself lead illustrate", and "the market-orchestrated model”.

\subsubsection{The State-Centered Model}

Despite the informational area, the "Ministry of Higher Education" additionally envelops a 
"National Committee for Higher Education and Research", which accomplishes decisions on the readiness, enlistment, and job course of staff. The leading group of trustees is made out of social affairs of controls, and each educate has its own specific board and divisions. No under $66 \%$ of all division people are picked by accomplices and 33\% by the Minister. All people are decided for a four years' time period. The leading group of trustees oversees matters identifying with solitary applications and progression. In addition, the Minister accountable for advanced education and research has cautioning chambers. There are also cautioning boards for ask about responsible for admonishing the minister on investigate approach and the masterminding of research spending designs, and likewise a "National Council for Universities", which has a section in selecting and giving residency to academic workforce at state supported schools. Opening new academic activities is the prohibitive obligation of the council.

\subsubsection{The Self-Rule Model}

As communicated over, "the self-rule model" gets from the chance to learn and look for after research. In this methodology, instead of the state-centered methodology, the school isn't a strategies for achieving external goals rather it is a target independent from anyone else (Olsen, 2007). Research and learning have their own common regard that isn't generally great with national, open, or social premiums. In the unadulterated kind of the Humboldt Ian show, the insightful network gets arranging from the state without being subjected to managerial measures. Regardless, today even countries that maintain this model don't have any huge bearing it in its utopic outline rather confine educational foundations through authorization and resource assignment. Schools have an abnormal state of freedom, and the standard feature of this style of organization is the nonappearance of "institutional coordination" between the universities' methods and political or present day targets. High guidance is driven with no plans for HR. This model effects the methodology for cutting edge instruction organization in Germany, Austria, and a couple of central European countries (Dobbins et al., 2011).

Each locale has a few territories of specialist: endorsing the status of advanced education foundations; directing the institutional structure through laws of advanced education and especially workforce organization, spending plans, and fund; affirming studies and managing exams; affirming ministers and presidents after their decision; affirming teachers. In a few locale, a portion of the administrative capacities are granted to college chambers whose part is like that of a leading group of governors. Also, in a few locale the whole workforce is utilized and affirmed by the college presidents. In all locale the interior spending plan is overseen autonomously by the organizations. The moderately little private division in German advanced education is subsidized by educational cost and private assets, in spite of the fact that at times the administration provides money related help. Private establishments are liable to nearby area direction also.

The UK course of action of advanced education fuses three sorts of schools: schools, colleges, and research associations. Universities oversee look into and teaching; schools revolve basically around training and respect "Bachelor's"Bachelor's and "Master's"Master's degrees 


\section{Macrothink}

(when in doubt not investigate degrees); examine establishments are a sort of ace school that distinctions moved degrees (Adkit, 2014).

The HEFC stipends schools bolsters as square permits and associations may disperse the endowments as they see fit, in light of the fact that they are used for study and research works out "the council is fit the bill for stipulate conditions for a piece of the give". The total spending plan for cutting edge instruction is directed by the organization. Inside the budgetary structure, and as shown by scattering criteria appearing in the give see, the HEFCE administering body in exchange with its staff settles on assignments for each specific establishment and reason. A huge segment of the arranging takes after a set condition, with the true objective that the best administrative staff has modestly confined meticulousness. In any case, the board achieves decisions as to utilization of certain organization approaches.

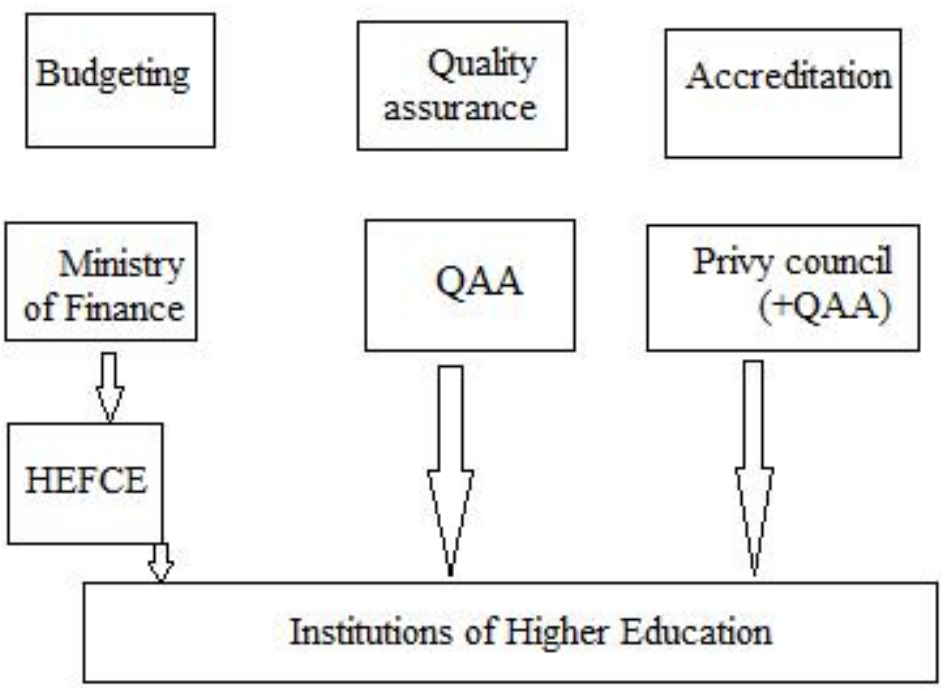

Figure 1. The UK governance structure

\subsubsection{The Market-Oriented Model}

The essential introduction of organization tending towards "the market-arranged model" is that universities work simply more viably when they fill in as cash related associations inside close-by and overall markets. The market-arranged model gets its inspiration from the business person approach, which expect that affiliations accomplish maximal capability in conditions of contention and a free market. In this model schools fight with one another for understudies and cash related resources. School chiefs view themselves as agents or makers heading a venture went for offering understudies academic organizations. The market-arranged model, all over also called the "entrepreneurial school" appear, uses private industry's organization measures of execution based financing. The school isn't a target independent from anyone else and neither does it establish open items. Or maybe, the school is viewed as a thing, an endeavor, and an indispensable resource. The governing body does not take measures to blueprint and plan the game plan of cutting edge training; rather, it propels contention and grows quality attestation and straightforwardness in academic 
foundations.

Changing advanced education into a buyer decent subject to the "imperceptible hand" of the free market may prompt privatization of the framework. Anyway the legislature can likewise be included and impact advanced education in a roundabout way by empowering rivalry and coordinating quality confirmation measures. Governments can present a strategy that empowers rivalry, for instance by managing budgetary help and coordinating apparatuses that influence the structure of estimating and enlistment in organizations of advanced education. Subsequently, in this model the government's administration is showed in a roundabout way. Rather than the state-focused model, which tries to move the advanced education framework by arranging HR and sanctioning directions and laws, in the present model the government's mediation is showed essentially in conceding impetuses to empower rivalry and exclusive requirements.

\section{Study Methodology}

The current research effort uses a comparative methodology. In view of information from the Bahrain, Egypt, Iraq and the UK. The qualities and shortcomings of each model are talked about, and the eventual fate of administration in light of nearby requests worldwide patterns. As one of the major international development institutions, the UNDP has been able to set the development agenda as far as the emphasis on the human dimension is concerned (Klingebiel, 1999: 179). The UNDP has a high profile on good governance. Furthermore, UNDP operates with a very broad definition of good governance. According to the UNDP characteristics of good governance include: participation, rule of law, transparency, responsiveness, consensus of orientation, equity, effectiveness and efficiency, accountability and strategic vision (UNDP 1997a: 4-5).

UNDP also plays a leading role in including the private sector and civil society as parts of the good governance agenda (UNDP, 1997b). Good governance is widely considered to be the primary means for achieving sustainable human development (UNDP, 1997a: 1). It is, in other words, one of the core concepts of UNDP's development policy. In addition, the concept of good governance has given rise to organizational changes within the structure of UNDP (UNDP, 1998: 102). UNDP has been at the forefront of the good governance agenda in recent years. The notion of good governance seems to be one of the main features of a more profiled UNDP with a sharper focus on a culture of cost-consciousness put forward by the UNDP administrator Mark Malloch Brown. In promoting the notion of good governance in the multilateral development system, UNDP acknowledge that notions like sustainable human development and good governance are "theory-laden" and "culture bound" (ibid, 109). In the same vein UNDP encourages the developing countries to develop their own views of good governance (ibid, 110). In other words, UNDP somehow has a reflexive position as regards the notion of good governance. Nevertheless, UNDP has elaborated an index, the Human Governance Index, which measures economic, political and civic governance (St. Clair, 2001). 


\section{Macrothink}

\subsection{Model of Governance in Bahrain}

In created nations, HEIs have adequate abilities to guarantee front line foundation and supported spending plans, which add to the accessibility of a satisfactory research condition. In those nations specifically, investigate motivators, financing, and specialized help have been enter components in upgrading the nature of logical research in HEIs. In the Arab world, there is most likely that higher education institutions have a main role to play in building the cutting edge state. HEIs have been and keep on being the principle wellspring of training for a developing number of understudies. Meanwhile, the quantity of HEIs has extended altogether to adapt to the expanded request, coming about because of the development in populace and the rising attention to the significance of instruction.

In Bahrain, "the Academic Accreditation Committee" was established in 2005 and the Relationship of Quality Assurance and Training was built up in 2008. It is important that the greater part of the previously mentioned boards of trustees for quality control and quality confirmation appreciate a specific level of self-governance; in any case, each is directed by its individual national service of advanced education or gathering for advanced education or is partnered with the legislature. The ongoing worldwide acknowledgment of the significance of keeping up guidelines of magnificence in inquire about in HEIs has included another test for the Arab instructive part. The Quality Assurance and Accreditation Council have the caution to demand and direct quality reviews of any part of value in accordance with content, plan, conveyance or appraisal of any showed program and the Academic Audit Committee is charged by the Quality and Accreditation Council to lead such reviews.

Every one of the administration models has points of interest and drawbacks. In the exemplary model where the scholastic network deals with its undertakings autonomously, scholarly opportunity and self-sufficiency in research and educating are kept up. Nations tending towards this approach do not implement methods for arranging and organizing advanced education. Also, opportunity of administration may conflict with open interests, which legitimize and subsidize most open scholarly organizations. In many colleges and higher trainings in Bahrain, the administration structure comprise of five bodies as clarified in Figure 2: 


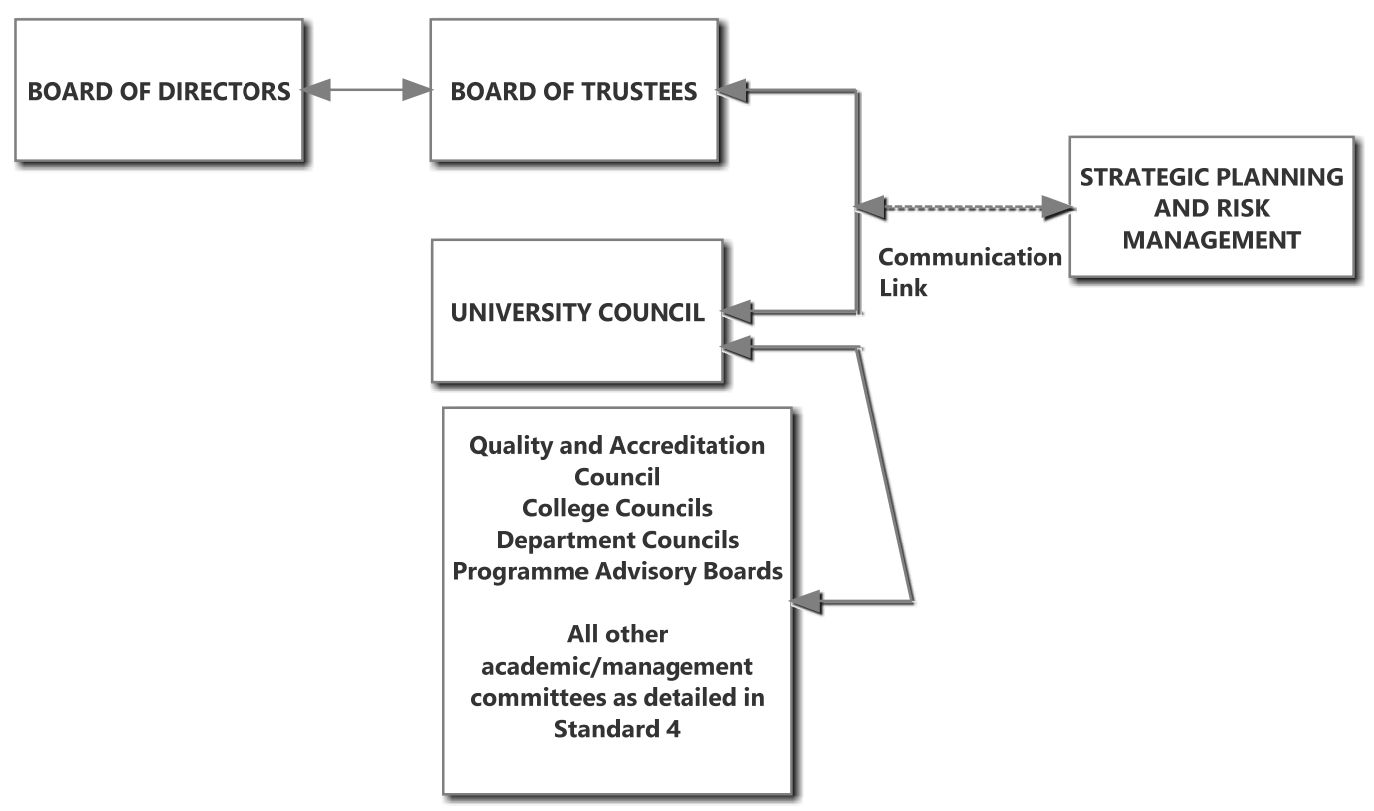

Figure 2. The administration structure of Higher Education in Bahrain

Governing body is successfully the subsidizing body of the University and its part is confined to managing money related issues. Leading body of Trustees is the most astounding representing body of the establishment. The focal point of the Board of Trustees is on guaranteeing that sound standards of administration are connected as opposed to being engaged with the nitty gritty administration of the University an errand which is the obligation of the University President and the University Council. In practicing its duties regarding the general key bearing of the University, the Board of Trustees administers the University's exercises; decides its vision and mission; encourages a situation in which the University's key needs can be accomplished; gives vital contribution on all material strategy or different issues influencing the University; sets up and screens frameworks of control and responsibility, including money related and operational controls and hazard evaluation; and audits and screens the administration of the University and its execution.

College Council and the Management Structure inside the University encourage lucidity in parts regarding scholastic honesty and nature of instructive arrangement and successful operational working of the University, the President assembles both the University Council and the University Management Committee. The President, as Chief Executive Officer in this manner has obligation and expert for the initiative, organization and administration of the University. The University Council is met by the President and its participation incorporates the Vice-Presidents, all Deans of Colleges.

Vital Planning and Risk advisory group is in charge of the advancement and execution of vital and operational plans; hierarchical structure and survey; observing of the execution of schools and offices and the University against concurred Key Performance Indicators (KPIs) and Critical Success Factors in quest for its vital needs; considering and prescribing to the 
Board of Trustees any recommendations for Memoranda of Understanding, associations or synergistic exercises to guarantee that such proposition have been liable to hazard evaluation, are unmistakably characterized and consistent with any legitimate or institutional prerequisites regarding due ingenuity and that the degree and constraints of such exercises are very much conveyed to all partners including understudies. keeping up oversight of the University's Risk Management Policy and its usage; and, giving normal reports to the Board of Trustees all through the session on all the above. This is especially critical as far as responding to hazard Risks which may affect the capacity of the University to accomplish its key destinations are recorded in a Risk Register. The Risk Register is a dynamic archive which records the idea of the hazard, the effect of the hazard on the University, the probability of the hazard happening and the moves being made to alleviate the hazard. All Colleges and Departments/Centers are required to distinguish hazards and propose activities to alleviate against the hazard. It is the duty of the people who contain the Strategic Planning and Risk Management Committee, and specifically the Head of Strategic Planning, to oversee chance and to guarantee that the Board of Trustees knows about any recognized hazard and the moves being made to address them.

\section{Research Findings and Results}

In Bahrain there are 4 open foundations of advanced education (Arabian Gulf University, Bahrain Polytechnic, College of Health Sciences, University of Bahrain) and 18 private and advanced education establishments. All organizations, have a sum of more than 38,113 understudies (HEC, 2014). The organizations in charge of keeping up a harmony between scholarly opportunity and supervision of advanced education are: The Higher Education Council (HEC) and "National Authority for Qualifications and Quality Assurance of Education and Training" (QQA). These are in charge of all scholastic, regulatory, and budgetary parts of advanced education. Besides, the HEC and the QQA, the organizations specifically accountable for the arrangement of advanced education, have a specific duty regarding the action and working of foundations of advanced education.

The HEC led by the Minister of Education and it has ten different individuals. The obligations of the HEC are in three region "enhancing the execution of colleges, observing and assessing arrangement, and controlling new investigation programs. The HEC is worried about college undertakings in different aspects- regulatory, logical, investigate and studentswhich incorporate the readiness of the general strategy for advanced education and logical research, making controls in regards to the affirmation of understudies to establishments of advanced education and additionally proposing alterations to the laws and directions of advanced education in light of the improvement of the general arrangements in the Kingdom, and issuing directions and resolutions sorting out the scholastic, money related and authoritative issues as for advanced education. Moreover, it sets the terms and criteria for the authorizing of various sorts of advanced education organizations including private advanced education establishments, gets ready yearly reports on advanced education execution issued by advanced education foundations and skilled legislative specialists, suggests fitting solutions for such execution and activities for its improvement, gets ready yearly reports for the bureau on advanced education and logical research status with important proposals and 
advancing private interest in advanced education" (HEC, 2018).

The British Accreditation Council has marked an agreement to examine Bahrain's colleges, in a critical extension of its universal exercises. The BAC will work with the nation's Higher Education Council to create documentation for accreditation, run workshops for colleges and prepare HEC staff, notwithstanding doing reviews of open and private establishments. The Bahrain understanding was marked by Paul Fear, the BAC's CEO, and Majed Bin Ali Al Noaimi, the nation's training priest. "The agreement speaks to a tremendous vote of trust in the thoroughness of BAC accreditation strategies and mirrors the high respect for the UK's notoriety for respectability and straightforwardness in instruction," Mr. Fear said. "This agreement will bolster the HEC in bringing measures up in advanced education and will offer certainty to both national and worldwide understudies thinking about concentrate in the kingdom of Bahrain."

The private colleges in Bahrain is a piece of the Higher Education division and it is add to set up the human capital as it is imperative to execute the vision of 2030. If there should be an occurrence of UK, The HEFC is dependable on planning and particular financing of uncommon tasks. It is exceedingly prescribed that advanced education bodies in Bahrain to subsidize particular innovative work of research-based strategy; fashioning connections between scholarly organizations and the network and business world; support of places for greatness and more to blasting the development. This planning arrangement will takes after a set recipe which serving the financial matters of information and making the interest in nationals.

As Hamdan, (2015), announced that the Arab colleges overpowering the shortcoming of financing and intensely reliance on government spending plan. In result, it is hard to set up the model of Research University and at last it impact the nature of graduate understudy. The colleges ought to apply the administration procedure to secure the trust from the financing bodies and pull in the gifts since it speak to the ideal condition for self-building.

The colleges in Bahrain ought to consider their vision and make it perfect with their methodologies and the real motivation behind college whether to the administration or to nation as a rule. The consistently change in the mission and techniques influencing their part being developed in this way, colleges ought to be steady in light of the fact that accomplishing systems taking long time.

To improve the straightforwardness in administration process, the colleges in Bahrain ought not to depend just on the legislature and charges keeping in mind the end goal to back their scholarly exercises. Rather, they should discover another technique for back, for example, imaginative activities and gifts. Along these lines, we recommend to help the maintainability, to spare $10 \%$ from the income for putting resources into making advantages for be wellspring of additional salary which empower the colleges to subsidizing their exploration tasks and improve the independence. Clearly, college isn't only to teach, hence we persuaded that they should have long haul intend to draw in the expert scholastic which they have solid resume in examine and in the meantime welcome or give grant to profoundly gifted understudies. 
Additionally in a similar edge, to keep up the straightforwardness, the colleges utilize the specialist to the Board of trustees which they are not chosen. While the partner demonstrate accomplished when a gathering of invested individuals spoke to reasonably in arrangement of sheets, for example, understudies, workers, scholastics, graduates, government and nearby networks. Furthermore, the Saudi corporate setting has unmistakable social highlights of having solid various leveled social structure (Al-Twaijry, Brierley, \& Gwilliam, 2002; Haniffa \& Hudaib, 2007) in which more noteworthy significance is typically appended to casual connections, for example, sovereignty and ancestral affiliations than formal CG and responsibility components like corporate sheets and their subcommittees (Hussainey \& Al-Nodel, 2008). The Saudi corporate setting is additionally described by concentrated proprietorship structures (mostly by government and families), denial of direct outside value property, and low levels of institutional possession, bringing about inadequate activism by investors and a powerless ability to actualize and authorize corporate controls (Al-Razeen \& Karbhari, 2004; Piesse et al., 2012).

World fiercely, there is an aggregate mindfulness with respect to the support of common network in driving and take an interest in taking choices in the HE establishments. The standards of popular government and consultancy is vital in deciding. These standards are upgrading the cooperation.

Drawing on bits of knowledge from institutional hypothesis, we contend that alternate points of view on administration are established on unmistakable rationales. In a general sense, these rationales constitute arranging standards in view of an arrangement of conviction frameworks and related practices (Scott, 2001). One of the fundamentals connecting vital operator speculations, for example, office and stewardship hypothesis is that they are established on what Watson (2006) alludes to as a "frameworks control" way to deal with confining authoritative substances. Basically these methodologies seek to augment control over human conditions by introducing associations as objective based controllable frameworks. Partner hypothesis accept partners have distinctive interests and it is along these lines imperative that the overseeing block is made of partner delegates (Kochan \& Rubinstein, 2000). Seemingly, these relevant difficulties bring up genuine experimental issues with respect to whether the 2006 Saudi deliberate consistence and revelation CG Code can enhance CG guidelines of Saudi recorded organizations.

Applying office hypothesis, administration implies ensuring that the administration element (or operator) runs and deals with the association for the most extreme advantage of one or various partners (or principals) inside a legitimate, supervisory, official, and moral system. Included among the numerous partners are investors, monetary foundations and banks, providers, customers, workers, and whatever other gathering that is influenced by the choices of companies. Joint effort between the organization and the partners is gainful for all gatherings. By applying the partner hypothesis to corporate administration, all partners partake during the time spent corporate administration; access to pertinent data, consistently and in an auspicious way, must be given. 


\section{Concluding Comments}

As a rule, the utilization of administration in HEIs has remarkable hugeness in Bahrain Administration additionally fortifies responsibility and regulates the conveyance of undertakings and administrations. Besides, it decreases the distinctions among college staff and builds instances of mergers and association among partners. The significance of administration, at that point, lies in the far reaching framework that, when put resources into legitimately, as per a methodical and logical approach, makes it conceivable to adjust to factors in the inner and outer condition.

In addition, it diminishes contrasts in perspective and expands combination among partners keeping in mind the end goal to help accomplish upper hand in the nature of the material and good results, and pick up a scholastic notoriety at the neighborhood, local, and universal levels. At last, administration encourages the college to get a worldwide accreditation.

The purpose of advanced education administration suggests the genuine task of force in fundamental initiative inside the school between the distinctive organization structures and administrative structures. The inspiration driving propelled instruction organization is to express the typical open interest and comprehend its targets, while characterizing the cutoff points of pro on a fundamental level and eventually-who will pick and what is at the point of convergence of decisions.

The universities in the Kingdom of Bahrain must play clear and specific roles in ensuring continuous production of knowledge. To work on the effective production of knowledge to those in need, and to ensure as much as possible the building of the capable individual in society. As well as the application of knowledge to solve the problems experienced by the fields of life in Bahrain. Universities may not be able to do those roles because of challenges such as increasing numbers of students, increasing numbers of unemployed graduates, and still providing traditional skills to the learners that do not has compatible qualify of individual to live and work in the era of globalization. According to modern procedure of governance, there is a great needs to review all the standards and requirements of the governance policies.

The application of governance in university institutions leads to positive changes affecting everything within them so that they can achieve objectives are efficient and effective and thus ensure its excellence and continuity as most of the universities that adopted the governance approach have increased. And profitability has increased and has gained positive results. The improvement and development is seen as a continuous process that does not end. Focus should increase on the participation and empowerment of all employees and thus instilling a sense of belonging to the institution in order to work with dedication and sincerity.

Based on the findings of the current study, we recommend universities which they are dedicate resources to research, to pay great attention to be aware that the development of the higher education sector is not complete in the absence of good governance for its institutions and in the absence of accountability and transparency. Good governance is not only concerned with the management of the university but also by establishing standards and governing mechanisms for the performance of all parties through. Establishing such standards 
should be stemmed from the Islamic culture that has the significant influence on Muslim believes and consequently on their behavior.

\section{References}

Hamdan, A. M. (2015). The road towards world class research universities.Arabic Rewards for social and humanity to encourage scientific research, 13, 65-104. Third cycle, Omran.

Boer, H., \& File, J. (2009). Higher education governance reforms across Europe. Centre for Higher Education Policy Studies (CHEPS).

Clark, B. R. (1983). The higher education system. Berkeley: University of California Press.

Commager, H. S. (1963). The university and freedom: "Lehrfreiheit" and "Lehrnfreiheit". The Journal of Higher Education, 361-370. https://doi.org/10.2307/1980014

Corcoran, S. (2004). Duty, discretion and conflict: University governance and the legal obligations of university boards. Australian Universities' Review, 46(2), 30-37.

De Boer, H., Huisman, J., \& Meister-Scheytt, C. (2010). Supervision in "modern" university governance: Boards under scrutiny. Studies in Higher Education, 35(3), 317-333. https://doi.org/10.1080/03075070903062849

Dobbins, M., \& Knill, C. (2009). Higher education policies in Central and Eastern Europe: Convergence toward a common model? Governance, 22(3), 397-430. https://doi.org/10.1111/j.1468-0491.2009.01445.x

Dobbins, M., \& Knill, C. (2014). Higher education governance and policy change in Western Europe: International challenges to historical institutions. Palgrave Macmillan. https://doi.org/10.1057/9781137399854

Dobbins, M., Knill, C., \& Vögtle, E. M. (2011). An analytical framework for the cross-country comparison of higher education governance. Higher Education, 62(5), 665-683. https://doi.org/10.1007/s10734-011-9412-4

Enders, J. (2004). Higher education, internationalisation, and the nation-state: Recent developments and challenges to governance theory. Higher Education, 47(3), 361-382. https://doi.org/10.1023/B:HIGH.0000016461.98676.30

Ferlie, E., Musselin, C., \& Andresani, G. (2008). The steering of higher education systems: A public management perspective. Higher Education, 56(3), 325-348. https://doi.org/10.1007/s10734-008-9125-5

Haskins, C. H. (1957). The rise of universities. Ithaca, NY: Cornell University Press.

King, R., Griffiths, P., \& Williams, R. (2007). Regulatory intermediation and quality assurance in higher education: The case of the auditors. Oxford Review of Education, 33, 161-174. https://doi.org/10.1080/03054980701259790

Kochan, T. A., \& Rubinstein, S. A. (2000). Toward a stakeholder theory of the firm: The Saturn partnership. Organization Science, 11, 367-386. 
https://doi.org/10.1287/orsc.11.4.367.14601

McLendon, M. K. (2003). State governance reform of higher education: Patterns, trends, and theories of the public policy process. In J. C. Smart (Ed.), Higher education: Handbook of theory and research, 18, 57-143. Netherlands: Springer. https://doi.org/10.1007/978-94-010-0137-3_2

Norton, A. (2012). Mapping Australian higher education. Carlton, Victoria, Australia: Grattan Institute. Retrieved from http://grattan.edu.au/wp-content/uploads/2014/10/816-mapping-higher-education-2014.p df

Olsen, J. (2007). The institutional dynamics of the European University. In M. Peter, \& O. Johan (Eds.), University Dynamics and European integration. Dordrecht: Springer. https://doi.org/10.1007/978-1-4020-5971-1_2

Pennock, L., Jones, G. A., Leclerc, J. M., \& Li, S. X. (2015). Assessing the role and structure of academic senates in Canadian universities, 2000-2012. Higher Education, 1-16. https://doi.org/10.1007/s10734-014-9852-8

Rowlands, J. (2013). Academic boards: Less intellectual and more academic capital in higher education governance? Studies in Higher Education, 38(9), 1274-1289. https://doi.org/10.1080/03075079.2011.619655

Schuetz, P. (1999). Shared Governance in community colleges. Eric Digests. 4.

Scott, J. (2006). The mission of the university: Medieval to postmodern transformations. Journal of Higher Education, 77, 1-39. https://doi.org/10.1353/jhe.2006.0007

Scott, W. R. (2001). Institutions and organizations, (2nd ed.). Thousand Oaks, CA: SAGE.

Shattock, M. (2013). University governance, leadership and management in a decade of diversification and uncertainty. Higher Education Quarterly, 67(3), 217-233. https://doi.org/10.1111/hequ.12017

Toutkoushian, R., \& Shafiq, M. M. (2010). A conceptual analysis of state support for higher education: Appropriations versus need-based financial aid. Research in Higher Education, 51(1), 40-64. https://doi.org/10.1007/s11162-009-9148-5

UNDP (1997a). Governance for sustainable human development. A UNDP Policy Document, New York: United Nations Development Programme, 1997.

UNDP (1997b). Reconceptualising Governance. Discussion paper 2, New York.

UNDP (1998). Public Sector Management, Governance, and Sustainable Human Development. Discussion Paper, New York: Management Development and Governance Division, Bureau for Policy and Programme Support, UNDP. Retieved from http://magnet.undp.org/Docs/!UN98-21.PDF/psm.htm.

UNDP (2000). Experiences and Lessons Learned, New. UNDP and Governance.

Vaira, M. (2004). Globalization and higher education organizational change: A framework for 


\section{Macrothink Institute ${ }^{\mathrm{TM}}$}

International Journal of Learning and Development ISSN 2164-4063 2018, Vol. 8, No. 4

analysis.

Higher

Education,

$48(4)$.

483-510.

Watson, T. (2006). Organising and managing work, (2nd ed.). Harlow, UK: Prentice Hall.

\section{Copyright Disclaimer}

Copyright for this article is retained by the author(s), with first publication rights granted to the journal.

This is an open-access article distributed under the terms and conditions of the Creative Commons Attribution license (http://creativecommons.org/licenses/by/4.0/). 